less austere surroundings, discussion was joined with others including the Chief Rabbi, whose explication of some of the relevant assumptions enabled the group to focus on the major theme of this publication, namely the relative importance of consent in the three traditions mentioned.

The Chief Rabbi's comments comprise one of the six chapters of this book which are based on the group's working papers, refined through discussion. The fundamental assumption which he makes is that of the 'absolute, intrinsic and infinite value of human life'. This assumption implies that 'a patient has no right to refuse medical treatment deemed essential by competent medical opinion for the preservation of his life or health, and his consent need not be procured for such treatment'. It also justifies withholding from a patient a fatal diagnosis - or rather, to be more accurate, it makes divulging such a diagnosis something which requires justification. These implications, clearly, are not those of the ethical assumptions of all non-Jewish doctors and patients. Why this is so is suggested in a chapter by Fr Brendan Soane on consent in the Catholic tradition, which places comparatively greater emphasis on the value of autonomy, and in a further chapter by Mr Peter Byrne, who mentions the classical philosophical assumptions which entered the Christian tradition. Mr Byrne's chapter goes on to examine difficulties raised on the one hand by the absolute value of human life in Judaism and on the other by the Catholic tradition's willingness to qualify this view. Difficulties about the Jewish tradition are raised in connection with the idea that selfsacrifice in a noble cause is praiseworthy, while criticism of the Catholic tradition takes the from of a philosophical variant on the old question of 'How far can you go, Father?', although in this case with implications for suicide rather than sexuality.

Doctors and patients unfamiliar with Jewish ethical assumptions about consent might also be ignorant of the Hippocratic. In a substantial historical chapter, their needs are met by Professor Polani, who argues that 'the issue of consent was apparently not considered until recent times' and suggests some reasons why the subject is now attracting more attention in Western culture, law and medical practice. An appended note to this chapter by $\mathrm{Mr}$ Ian Kennedy takes issue with Professor Polani's conclusions, at least as far as the law is concerned, and goes on to make some useful suggestions concerning the law, consent and minors. This last subject is also discussed in Fr Soane's contribution and in the book's final chapter, by Dr Eliot Philipp and Dr Stewart Johnson, which reviews consent in relation to various aspects of medical practice.

These summary comments fail to do justice to what is a most lucid, readable and informative book, and also to the careful arguments, particularly of Professor Dunstan, the Chief Rabbi, Mr Byrne and Fr Soane. Inevitably there are loose ends. In his introductory chapter, which attempts to draw together some threads of the discussion and give a pattern to the questions it raised, Professor Dunstan makes out a helpful case for use of the term 'covenant' rather than the narrower 'contract' in talking about the doctorpatient relationship within which issues of consent commonly arise. This suggestion receives some support in Professor Polani's chapter, but is somewhat dented when one of the authors of the final chapter records that, in reply to his enquiries, the Medical Defence Union stated, 'we do not think the word "covenant" would be at all appropriate in the context of relations between doctor and patient'. Such a magisterial response from the Hippocratic tradition may simply reflect difficulties arising from certain legal uses of the word, as Professor Dunstan suggests, or it may reflect a broader English philosophical conservatism: one's impression is that the term has proved less unacceptable within the more open texture of transatlantic thought. On the other hand this particular loose end also suggests what seems most obviously lacking from this book, namely the 'overheard conversations' themselves, to use the phrase with which the introductory chapter tantalises the reader. Professor Dunstan ends that chapter by stating that 'there is still room for men of strong convictions, differing convictions, calmly and in amity to exchange ideas'. Greater evidence of the actual 'exchange' would certainly have been interesting. As it is, the exchange with which we are presented is rather more like that of diplomatic notes. But admittedly, they are notes for the most part of good quality and make stimulating reading, for which we should be grateful.

KENNETH M BOYD Scottish Director Society for the Study of Medical Ethics.

\section{Who Should Decide? Paternalism in Health Care}

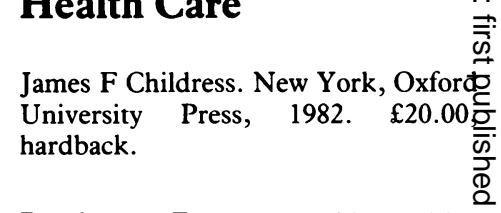

People vary. Every reasonably sensitive् and understanding doctor soon discovers that some patients want to hear about risks and options and also to $\overrightarrow{\mathrm{C}}$ take part in difficult decisions - so far aw this is possible for the untrained anf inexperienced person. But he also seeફ̧ that others (no matter how intelligent $-\vec{D}$ and regardless of what they may have said before they became ill and frightened) long for firm, reassuring, professional decisions - which they hope will be based on a mixture of skilland kindness and taken on their behalk with a minimum of discussion. This has surely always been the ethic of traditional orthodox medicine, though we may not always have lived up to it. $\infty$

So why has 'paternalism' recently become almost a dirty word among some doctor watchers? Partly, it seems because we are less trusted than we usec to be to make sensible decisions - and partly because of a general lack of awareness of how 'full disclosure of alR relevant facts' - which sounds fine ins theory - often turns out to be callous in practice. The idea that some patients must suffer, if necessary, in order thap. the principle of autonomy (rather than paternalism) may remain inviolate is aş unattractive to most caring doctors as ito is to most distressed friends and relatives. Moreover, a direct question to the patient as to how much informations he wants - though sometimes helpful often merely serves to sow hurtful seeds of doubt, fear and conflict and to engender a feeling of inadequacy.

So what's to be done? How much help can a practising doctor expect from a painstaking philosophical analysis such as this one by James Childress NW Professor of Religious Studies and Medical Education at the University of Virginia and 'a well knownt contemporary ethicist'? Probably not as much as from a good pragmatic doctor who has learned when to speak and when to keep silent; who has profited from his mistakes; and who fully appreciates the extraordinary subtletie $\mathbb{B}$ and paradoxes of how different patients react - often ambivalently - under different circumstances. Nevertheless 0 the book is highly recommended for its overall balance, thorough scholarship 
and thoughtfulness. There are 375 references (many carefully annotated) and 22 case histories to highlight various ethical dilemmas.

Of course, like everything else, the more the subject is studied, the more difficult and complex it becomes. Attempting to classify different kinds of paternalism, Childress suggests that paternalism may be hard or soft, active or passive, pure or impure, restricted or extended, direct or indirect, and so on, until we are in danger of getting bogged down in sterile analysis and endless escape clauses designed to allow for occasional (or not so occasional) exceptions to general ethical principles.

The subject is difficult, emotive and replete with opportunities for misunderstanding - due partly to semantic difficulties. Even so, it is not easy to see exactly where Professor Childress stands with regard to paternalism, nor when he is content whisper it softly - to leave matters to the discretion of the individual doctor. In the final sentence of his preface, for example, he states 'Our acts, policies and practices in health care should express care and concern on the one hand, and respect for persons on the other - in short, limited or constrained paternalism'. Amen to that. Would that all our critics held the same enlightened view. Yet at times you get the feeling he is taking quite a different view. For example, 'Nowhere is paternalism more rampant than in the care of patients who are terminally ill or dying'. And when discussing how 'paternalism' is to be defined, he insists on including in his definition, 'a refusal to acquiesce in a person's wishes, choices or actions . . . This puzzles me. Try as I might, after reading the whole book carefully I was still unable to understand why this alarming idea of going against the patient's wishes should be included in the definition of something that he approves of, provided it is 'limited or constrained'. How limited? How constrained? It seems that when the chips are down, we are still stuck with our old friends, compassion, compromise and common sense.

THURSTAN B BREWIN Institute of Radiotherapeutics and Oncology, Glasgow.

\section{Medicine, Morals and the Law}

Sheila McLean and Gerry Maher. England, Gower, 1983. £12.50, hardback
It is a promising idea for a medical person and a legal person, both interested in moral issues, to get together and produce a collection of joint essays on morals, ethics, medical science, law and practice. Medico-legal matters ought wherever possible to be dealt with in such an interdisciplinary manner.

The authors examine many contemporary issues, and offer a number of opinions and conclusions. When does life begin, they ask, at fertilisation, at implantation, or when? Is it satisfactory that in abortion neither the mother nor the child nor the father appear to have any legal 'rights'? Euthanasia (in so far as it takes place) and switching off the life support machine are matters best left to the decision of the individual doctor, the authors believe and should not be regulated by law. In view of the desirability of autonomy and of the choice inhering in the patient, as a dignified human being, he should always be informed of the facts of his situation, they maintain. And experimentation is necessary for medical advance, but should be limited by the principle of utilitarianism. The authors believe sterilisation and contraception should be a matter for the individual, who should be entitled to control his or her capacity for reproduction. The answer to the flood of negligence actions is to seek to improve mutual patient-doctor trust. Patients expect too much; the standard imposed by the law upon doctors is too low. And, the authors conclude, decision-taking in medicine relies too heavily upon technical remedies rather than preventive medicine.

This book is interesting, readable, quite well documented, and seeks to propound theoretical and viable principles for resolving medico-legal problems, principally those of a moral or ethical character. The 'solutions' offered are not terribly consistent nor profound. They sometimes give the impression of compromise, and they sometimes seek to evade the moral and ethical issues. But they undoubtedly make a contribution to knowledge and thinking and understanding.

The text is a modern typescript reproduction, with unjustified pages, not a bad production of its kind, but not comparable to the printed page.

ALEC SAMUELS

Faculty of Law, University of Southampton.

\section{Law and Ethics in the Medical Office}

Marcia A Lewis and Carol D Warden. Philadelphia, F A Davis Co, 1983. $£ 11.20$ paperback.

Some books from the United States require translation; this book requires translocation. The form and content of this manual would make it very useful for medical secretaries and receptionists if only it dealt with the topics as they might apply to medical practice in the United Kingdom.

The book is divided, perhaps arbitrarily, into two equal sections: one dealing with the law, the other with ethics. In the medical office the legal implications of employment and bookkeeping are as important as the medicolegal aspects of consent, confidentiality and litigation. The section on ethics, as we might expect, covers the history of ethical codes and discusses the features and constraints when considering action in abortion, sterilisation and euthanasia. The form is attractive. I admit to a liking for statements of learning objectives and each chapter of this book opens with a summary of the knowledge which should be absorbed by the reader on completing the chapter. The function of this book as a teaching aid and instruction manual is enhanced by the discussion questions posed at the end of each chapter.

Both the legal and ethical sections can be adversely criticised. Although some aspects of the two sections are common to medical practice on both sides of the Atlantic, the differences become distracting. The details given about fee collecting are irrelevant and, of course, the names of the posts and duties in the US medical office are strange to us. However, I commend the form and layout used in this book, the clear definitions of various terms in law and ethics and the easy access to references within the text as well as for further reading.

The experience of one of the writers as a patient seems to have initiated this publication and may explain the proper preaching it contains to all medical office staff of the need for real caring as well as sensitivity to patients' feelings. References are made to the American Association of Medical Assistants and I know the Association of Medical Secretaries in the United Kingdom has an established link with this organisation. Although this US publication will be of little use to the staffs in health centres and hospitals in 